PORTIONS OF THIS REPORT ARE ILLEEIBLE. I!

has been reproduced from the best ayaliable

copy to permit the broadest possible avait.

no ms *

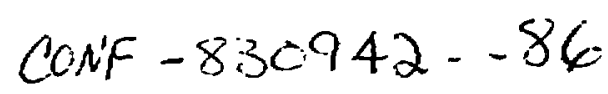

\title{
POINT DEFECT PRODUCTION AND ANNIHILATION IN NEUTRON-IRRADIATED ZIRCONILA*
}

\author{
S. R. MacEwen, R. H. Zee, R. C. Birtcher** and C. Abromeit ${ }^{+}$ \\ Atomi c Energy of Canada Limited, Chalk River Nuclear Laboratories \\ Chalk River, Ontario, Canada \\ * *Materials Science and Technology Division, Argonne National Laboratory \\ tHahn-Meitner-Institut, 1000 Berlin 39, FRG
}

$\operatorname{CONF}-830 \subseteq 42--86$

DES4 013426

May 1984

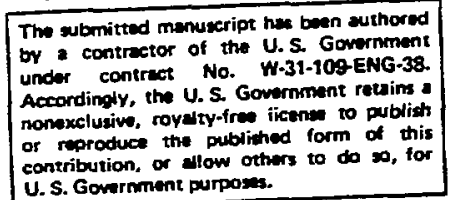

U.S. Government purposes.

\section{DISCLAIMER}

\begin{abstract}
This report was prepared as an account of work sponsored by an agency of the United States Government. Neither the United States Government nor any agency thereof, nor any of their employees, makes any warranty, express or implied, or assumes any legal liability or responsibility for the accuracy, completeness, or usefuiness of any information, apparatus, product, or process disclosed, or represents that its use would not infringe privately owned rights. Refermanufacturer, or otherwise does not product, process, or service by trade name, trademark, mendation, or favoring by necessarily constitute or imply its endorsement, recomand opinions of authors expressed htates Government or any agency thereof. The views United States Government or any agency theref not necessarily state or reflect those of the
\end{abstract}

Submitted to the Third Topical Meeting on Fusion Reactor Materials, Uct. 1983, Al buquerque, NA; proceedings to the J. Nucl. Mater.

*Work supported by the U. S. Department of Energy. 
PUIHT UEFECT PKLOUCTION ANU ANNIHLLATION IN MEUTKON-IKKADIATED ZIKCONIGH

S.K. HaCËnEN, K.H. ZEE, K.C. BIRTCHEK+ and C. ABKOMEIT ${ }^{++}$

Atumic Energy of Canada Limited, Chalk River Nuclear Laboratories, Chalk kiver, Untario, Lanada. - +haterials Science and Technology, Argonne National Laboratory, Argonne, IL bu439 U.S.A.

+ Hahn-Meitner-Institut, 1000 Berlin 39, FkG.

Wigh-purity $\mathrm{Zr}$ has been irradiated to a dose of $2.2 \times 10^{21} \mathrm{n} / \mathrm{m}^{2}$ ( $E<0.1$ MeV) using the puised spallation source at IPNS. Electrical resistivity was monitored continuously during irraaiation. The saturation resistivity, found from a linear extrapolation of the camage-rate curve Deiween four and five ns2.m, is found to be 35 ns.m. However, comparison with data From the literature shows that the normalized danage-rate curves from five experiments at different temperatures I $77 \mathrm{~K})$ and with different neutron sfectra, all fall on the same common curve. A saturation rēsistivity of $100 \mathrm{n} \Omega . m$ is found from the high-dose, linear part of this curve. A spontaneous recombination volume in the range 280 to 400 atomic volumes is found using the theory of Dettmann, Leibfried and Schroeder and the saturation resistivity of $100 \mathrm{n}$ :-m. Post-irradiation annealing has been cone up to $300 \mathrm{~K}$ using stepped, isochronal anneals. The recovery spectruin is in redsonable agreement with previous work, showing a large peak near luU $K$, and two swaller peaks at $160 \mathrm{~K}$ and $250 \mathrm{~K}$.

1. INTKODUCTION

Irradiation of crystalline solids by energetic particles produces vacancies and interstitials in pairs known as Frenkel defects. For low energy particles, such as electrons, isolated Frenkel pairs are produced rancomly; with heavy ion or neutron irradiation the derects are produced in cascades with high concentrations of defects. Each point defect is characterized by a volume surrounding it in which a point defect of the opposite sign is unstable and spontaneously recombines without thermal activation. Experimentally, the spontaneous recombination volume, $v_{r}$, can be determined by measuring electrical resistivity, 3 , as a function of irradiation dose, $\phi t$, at tenlperatures where neither the vacancy nor the interstitial is nobile. The paraweter of interest is the saturation resistivfty, $\Delta \rho_{s}$. which is comnonly found from an extrapolation of the admage rate do/dot, to zero.
Saturation resistivities for neutronirradiated $2 r$ have been reported previously from four experiments: kosenbaum et al. 1 give $\Delta \rho_{\mathrm{S}}=24 \mathrm{n} \Omega . \mathrm{m}$ for $\mathrm{Zr}$ irradiated at $7 \mathrm{~K}$, Vialaret et al..$^{2}$ report $\Delta f_{S}=100 \mathrm{n}$ R.s for irradiation at $24 \mathrm{~K}$, mile Nakagawa et al. ${ }^{3}$ and $K$ Tabunde and Coltman ${ }^{4}$ give values of zou $n$. n and $47 \mathrm{n} \Omega . m$, respectively, for irradiation at $4.5 \mathrm{~K}$. It has been suggested ${ }^{3}$ that the large range of $\Delta \rho_{s}$ measured (and thus of $V_{r}$ calculated) may originate from differences in irradiation temperature. Other possible sources for the discrepancy could be trace impurities, spectrum effects, or siuply the difficulty in extrapolating the damage-rate curves. The last would be most significant for experiulents done to low total cose, and thus one unight question the low values of $\Delta \mu_{s}$ reported by Rosenbaum et al. ${ }^{1}$ and by $K l$ labunde and coltiman ${ }^{4}$. However, the experiments of vialaret et al. 2 and Nakagawa et al ${ }^{3}$ extended to hiyh doses 
and both report linear danage-rate curves after an initial transient, yet the values of tis reported fifier by a factor of two.

The vojective of this work is to obtain daludye-riate curves for high purity $\mathrm{Zr}$ at luw tellperature $(5 x)$ using two different aeutron spectra, and thus to clarify the efrects of irradiation temperature and neutron energy on $V_{\text {:.. }}$. This paper will report only the results sotained at the kadiation Effects Facility at iPNS; data from an experiment at sTHS ara given in a comparison paper by Guinan et al. ${ }^{j}$.

\section{EXPEKK IHENTAL TECHNIQUE}

Marz-grade $\mathrm{Zr}$, obtained from the Materials kesearch Corpuration, was further purified using the electrotransport process ${ }^{6}$. Samples were cold-rulled to a thickness of $0.05 \mathrm{~mm}$, and then cut into $0.25 \mathrm{~nm}$ wide strips; $30 \mathrm{man}$ long. The wire was chenically cleaned before annealing in a vacuum of $10^{-5} \mathrm{~Pa}$ for $1 \mathrm{~h}$ at $1000 \mathrm{~K}$. The initial resistivity of the sample, $\rho_{0}$, lat $5.2 \mathrm{~K})$ was $2.6 \mathrm{nizm}$, and its resistivity ratio was 102 .

Irradiation was carried out at the Intense Pulsed Meutron Source (IPNS) at the Argonne Mational Laboratory. The specimen was maintained at $5.2 \mathrm{~K}$ in a target chamber that was surrounded by liquid helium and filled with hel ium exchange gas to ensure effective heat transfer between the specimen and the cryogenic 1 iquid. A calibrated Cu-Au 0.2\% Fe thermocouple was used to monitor the temperature of the specimen. The sample was irradiated to a total dose of $2.2 \times 10^{21} \mathrm{n} / \mathrm{m}^{2}$, with an average flux of $1.27 \times 10^{16} \mathrm{n} / \mathrm{m}^{2} . \mathrm{s}$; the neutron spectrum has been reported previously ${ }^{7}$.

stepped, post-irradiation, isochronal annealing was conducted up to $300 \mathrm{~K}$, with the specimen hela at each annealing temperature for 30u s. All resistivity measurements mere made at $5.2 \mathrm{~K}$.

\section{KESULTS}

The change in resistivity induced oy irradiation as a function or neutron cose is given in Figure 1. Failure of the datd-loyylny systen resulted in the luss of clata from $6 \times 10^{19}$ to $4.3 \times 10^{20} \mathrm{n} / \mathrm{m}^{2}$, and a perturbation of unknown origin produced a small tiuctuation in the camage rate near $1.5 \times 1 u^{21} \mathrm{n} / \mathrm{n}^{2}$. The danage-rate vs. danage curve, Figure 2, was obtained by smoothing a cubic spline fit to the data, eliuinating the points near the perturbation. As seen in Figure 2, the damaye-rate initially decreased very rapialy, nowever this transient lastea for only i $U .2 \mathrm{n}$ :...tl. Tinereafter, the curve was sliyhtly concave.

Figure 3 shows the results of the postirradiation annealing. Three annealing praks are evident: a large one at $=100 \mathrm{~K}$, and two smaller ones at $\imath i 60 k$ and $\sim 250 k$. The total amount of recovery up to $300 \mathrm{~K}$ was $70 \%$.

\section{DISCUSSION}

The general shape of the camage-rate curve, Figure 2, is in agreenent with curves reported for other hep and bec metals $s^{3}$. The very rapia initial transient is generaliy attributed to a deviation from Matthiessen's rule and typically lasts for $\Delta p \approx U .1$ o. An initial camaye rate has been deternined from $F$ igure 2 froul a swooth extrapolation of the camage-rate curve, after the initial fast transient, back to $u=u$. Linear axtrapolation of the data between 4 and $5 n \Omega m$ to zero damage-rate gives a saturation resistivity of 35 nsilu. For comparison, figure 2 and damage-rate curves taken fron the literature have been normalized by their inizial damage rates. Table I 1 ists the relevant. parameters and the nomalized curyes are shown in Figure 4.

Within the uncertainty of the detemuination of the initial damage rates $(\approx 10 ;)$ all ata with the exception of those of Nakagawa et al ? fall within a single band. All show a transient 
TABLE I IKKAD:ATION DAMAGE FUK ZIKCUNIUH

\begin{tabular}{|c|c|c|c|c|c|}
\hline AUTitOR & TEMP. (K) & $p_{0}(n:=n)$ & $\begin{array}{l}\text { INITIAL :DANAAGE } \\
\text { KATE }\left(10-31 \therefore \mathrm{m}^{3}\right)\end{array}$ & $\Delta p(n: \ldots+n)^{(a)}$ & $\begin{array}{l}\text { DUSE } \\
|n: \ldots a|\end{array}$ \\
\hline $\begin{array}{l}\text { Kosenbaunl et al. } \\
\text { Vialaret et al. } \\
\text { Nakagawa et al. } \\
\text { Kldbunde et al. } \\
\text { Guinan et al. } \\
\text { This work }\end{array}$ & $\begin{array}{r}77 \\
24 \\
4.5 \\
4.5 \\
4.2 \\
5.2\end{array}$ & $\begin{array}{l}-. \\
1.8 \\
5.6 \\
3.0 \\
2.5 \\
2.5\end{array}$ & $\begin{array}{l}18.0 \\
35.0 \\
24.1 \\
25.0 \\
63.5 \\
23.5\end{array}$ & $\begin{array}{r}24 \\
100 \\
2100 \\
47 \\
100 \\
35\end{array}$ & $\begin{array}{l}5 \\
22 \\
54 \\
34 \\
10 \\
b\end{array}$ \\
\hline
\end{tabular}

(a) from linear extrapolation of the data at the highest dcse of the experiment.

wrich lasts for ip : 2 po, followed by a linear ragion, if the experiment was continued to a sufficiently high dose. It is significant that the data of Vialaret et al.2 (which extends to twice the dose shown in Figure 4 ) and those of Luinan et al. 5 nave the same final, linear slope, even though the initial damage rates differ by about a factor of two. Table I shows that Nakagawa's experinents were done using $\mathrm{Zr}$ that was significantly less pure, as evidenced by the $\rho_{0}$ value, than that employed by other workers. Thus, it nay be that the effect of trapping or clustering has lowered the final slope of the damage curve (see Averback et al 8 ).

If one applies the theory of Dettrmann, Leibfried and Schroeder ${ }^{9}$ for neutron-irradiated solids, it is found that $\ln 2 \leq C_{s} \cdot V_{r} \leq 1$, where $C_{s}$ is the concentration of Frenkel pairs at saturation. The range for $C_{s} \cdot V_{r}$ is determined by the concentration of defects in a cascade. Burger, Meissner and Schilling 10 have proposed that the transient part of the normalized damage-rate curve resuits from a focussing mechanism that is sensitive to the presence of dislocations and impurity atoms. They claim as well that the linear portion observed for most metals is independent of microstructure. With this interpretation, a value of $\Delta \rho_{S}=100 \mathrm{n} \Omega . m$ found from an extrapolation of the high dose data of figure 4 should be the iast appropriate for high purity $Z r$. With $C_{S}=\Delta \rho_{S} / \rho_{F P}$ and PFP $=4 \times 10^{4}$. one finos $c_{s}=2.5 \times 10^{-3}$ and $280 \leq v_{r} \leq 400$ atomic volumes. The al ternative interpretation of the data, that the initial slope of the normalized damage-rate curve is representative of the spontaneous reconibination process, leaus to unreasonably high values for $V_{r}$ (1suu to lyuu atomic volumes), and necessitates interpretation of the subsequent large aecrease in slope in terms of some new mechanisa, such as clustering.

The results of post-irradation annealing, Figure 3, are in general ayreement with previous stuaies $1,2,11$. The large peax at $\sim 100 \mathrm{~K}$ is generally attributed to the migration of free interstitials, as suggestea by ively $\$ 1$. The origin of the other two peaks is less certain. Hood ${ }^{12}$ has suggested that the lower 11 mit for the migration eneryy of free vacancies in $\mathrm{Zr}$ to be $1 \mathrm{eV}$, which implies that vacancies are inmobile below $300 \mathrm{~K}$. Thus, the two peaks observed in the range $150 k$ to $260 k$ are probably assocjated with the dissocation of interstitial clusters or interstitial-solute complexes.

\section{CONCLUSIUNS}

1. The nornalized danage-rate curves for neutron-irradiated, high-purity $\mathrm{Zr}$ are independent of irradiation temperature and neutron spectrum for temperatures up to $77 \mathrm{x}$.

2. The upper limit for the spontaneous recombination volume in $\mathrm{Zr}$ is 400 atoruic vol umes.

3. Annealing peaks in the ranye $150 \mathrm{k}$ to $260 \mathrm{~K}$ are most likeiy caused oy the decanposition of interstitial complexes. 


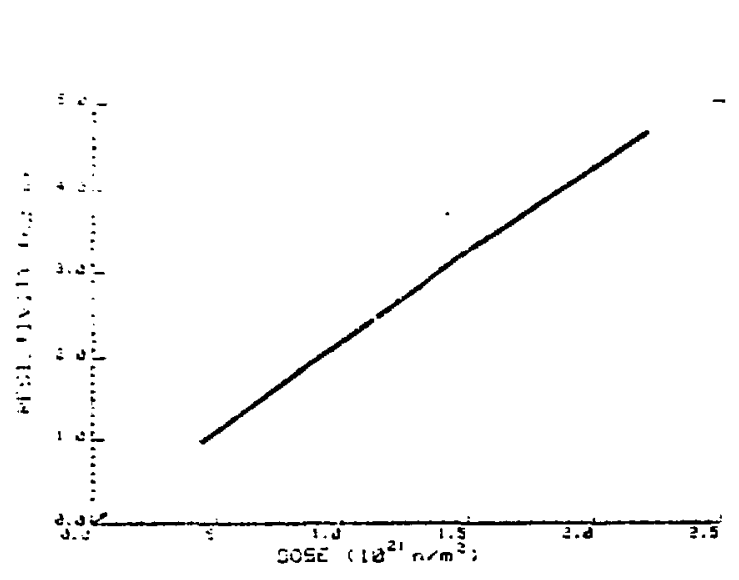

FELUKE 1

Shulige in isisitivity as a function of neutron flueng: in zirculliull irradiated at b. $2 k$ at IPHS.

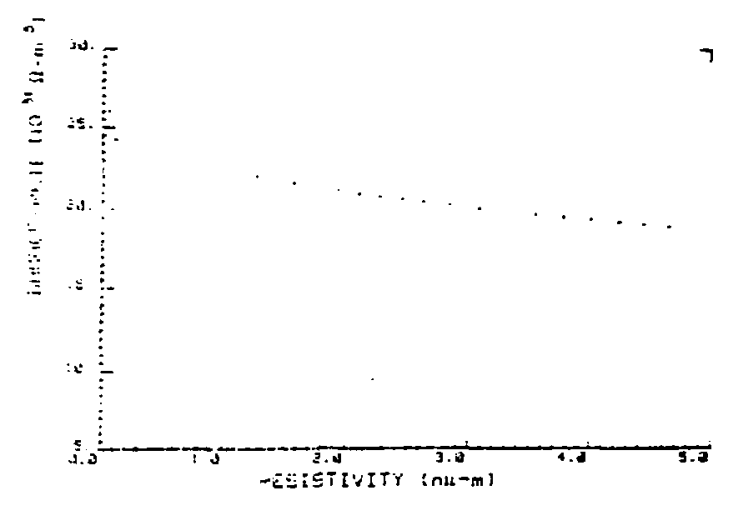

Filiokt 2

bisinge ratie versus chanue in radiation-inauced tesiszivity rur atroniull.

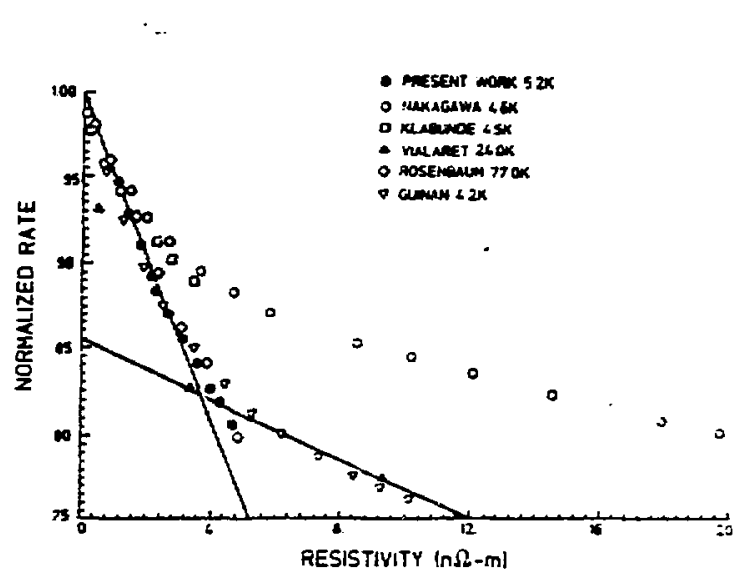

FIliliki 4

Nomalized dallage rate curres for variuus neutron irradiation stiaies.

Post-irradiation antiolilly results sliublily recuvery peaks at luo $k$, inu $k$ and cou k. 


\section{ACKNOKLEOGEMENTS}

We would like to thank Mr. J.F. watters of CoNL for his help in preparing the specimen.

\section{REFEKENCES}

1. M. Rosenbauln, E.A. Bisogni and T.H. Blewitt, j. Nucl. ilater. 48 (1973) 201.

2. P. Vialaret, F. Moreau, A. Bessis, C. Diliitror and 0 . Dimitrov, J. Nucl. Mater. $55(1975) 83$.

3. H. Nakagawa, W. Mansel, K. Böning, P. Kosner and G. Voyl, Phys. Kev. B 19 (1979) 742.

4. C.E. Klabunde and K.K. Coltman, Jr., j. Hucl. Mater. $108 / 109$ (198Z) 183.
5. it.W. Guinan and K.H. Zee, this voluta.

б. K.H. Zee and j.F. Watters, HECL-abbi \{19yj\}.

7. K.C. Birtcher, T.H. Blewitt, M.A. Kirk, T.L. Scott, B.S. Brown and L.K. Greenwood, J. Nucl. Mater. ius/lug (1982) 3.

8. K.S. Averoack, K.L. Merkle and L.d. Thoimpson, aad. Effects bl (1tul) yl.

9. K. Dettman, $\dot{3}$. Leibfried and $K$. Schroeder, Phys. Stat. Sol. 22 (1967) 433.

10. G. Burger, H. Meissner, and H. Schilling, Phys. Stat. Sol. 4 (1964) 281 .

11. H.H. Meely, Can. J. Phys. 46 (1968) sżl.

12. G.M. Hood, J. Wucl. inater., 96 (1981) 373. 